\title{
Innovating Teaching Practices in Legal Education: A Research-Based Faculty Development Path
}

\author{
Luigina Mortari ${ }^{1}$, Alessia Bevilacqua ${ }^{2}$, Roberta Silva $^{3}$, Fedra Alessandra Pizzato $^{4}$ \\ University of Verona (Italy)
}

\begin{abstract}
Within legal education, teaching innovation is currently aimed at supporting the development of students' reflective, critical thinking and problem-solving skills, which are essential for a profession characterized by a sharply increasing complexity.

The main feature of the individual coaching proposed by the Teaching and Learning Center of the University of Verona in response to the need of a Legal science professor to innovate his teaching practices is constituting itself as educational research.

Due to the evidence gathered through peer observation and the analysis of discursive practices, it was possible to support him in elaborating an authentic task to be solved by students through a cooperative and argumentative approach. This strategy allowed the instructor to achieve his two objectives: to increase the students' engagement and to facilitate the construction of an argumentative thought, starting from the analysis of the sources of law.

Results allowed to highlight how faculty development paths that include hetero-evaluative strategies facilitating reflective and metacognitive processes can lead to an improvement in teaching practices. The keystone lies in the possibility of acquiring both scientific evidence and an in-depth awareness of the strengths and weaknesses of individual teaching practices.
\end{abstract}

Keywords: discursive analysis; educational evaluation; higher education; peer-observation; teaching and learning centre. 